Савицкий С. А.

S. A. Savitski

РУССКАЯ ЭМИГРАЦИЯ КАК ИНИЦИАТОР ФОРМИРОВАНИЯ

НЕОФИЦИАЛЬНОГО КУЛЬТУРНОГО СООБЩЕСТВА В СССР

\title{
RUSSIAN EMIGRATION AS A MECHANISM OF FORMING UNOFFICIAL CULTURAL COMMUNITY IN THE USSR
}

Савицкий Станислав Анатольевич - кандидат искусствоведения, доктор философии, директор Центра современного искусства Факультета свободных искусств и наук Санкт-Петербургского государственного университета. E-mail: stassavitski@yahoo.com.

Mr. Stanislav A. Savitski - Candidate of sciences (theory and history of art), PhD, director of Center for Contemporary Art, Faculty of Liberal Arts and Sciences, Saint Petersburg State University. E-mail: stassavitski@yahoo.com.

Аннотация. Статья посвящена одному из ключевых эпизодов интеллектуальной истории культуры позднего социализма - социокультурному механизму формирования неофициальной культуры. Нонконформистское культурное сообщество, сосуществовавшее с официальными художественными институциями, образуется под влиянием нескольких существенных факторов. Один из них контакты с русской эмиграцией: как представителями первой и второй волны, так и с теми, кто покинул Советский Союз в 1970-е - начале 1980-х гг., пополнив ряды третьей эмиграции. В статье анализируются культурные практики взаимодействия эмиграции с неофициальным сообществом, повлиявшие на его создание и развитие.

Summary. The article is devoted to one of the key episodes of the intellectual history of the Late-Soviet culture that is the sociocultural mechanism of a formation of the unofficial culture. The Nonconformist cultural community that coexisted with the official artistic institutions was created under the influence of a few essential circumstances. One of them was an interaction with the Russian emigration: as with the representatives of its first and second waves, as well as with those who left the Soviet Union in the 1970s and early 1980s and were involved in the activities of the third émigrée milieu. The article focuses on the analysis of the cultural practices of interaction between the emigration and the unofficial community, which influenced its creation and its evolution.

Ключевые слова: интеллектуальная история культуры, поздний социализм, неофициальное сообщество, русская эмиграция.

Key words: intellectual history of culture, Late Socialism, unofficial community, Russian emigration.

УДК 821.161 .1

В формировании неофициального культурного сообщества, сыгравшего важную роль в истории позднего социализма, одним из ключевых эпизодов, предопределивших последующее развитие событий, стало налаживание связей с русской эмиграцией. Безусловно, независимая культура возникала, прежде всего, под воздействием внутренних политических и социокультурных факторов. Тем не менее сложно переоценить значение контактов тех, кто остался в СССР, с друзьями и единомышленниками, покинувшими родину в 1960-80-е гг. Без таких журналов, созданных представителями «третьей волны» эмиграции, как «Синтаксис» Андрей Синявского и Марии Розановой, «Эхо» Владимира Марамзина и Алексея Хвостенко или «А-Я» Игоря Шелковского и Александры Обуховой, сложно представить литературную и культурную ситуацию брежневского периода и последних лет существования советского государства. Что и говорить, программная статья Бориса Гройса «Московский романтический концептуализм», первоначально напечатанная в машинописном журнале «37», 
Савицкий С. А.

РУССКАЯ ЭМИГРАЦИЯ КАК ИНИЦИАТОР ФОРМИРОВАНИЯ НЕОФИЦИАЛЬНОГО КУЛЬТУРНОГО СООБЩЕСТВА В СССР

именно после републикации в журнале «А-Я» сформировала представление о том, что в Москве существует влиятельное художественное направление, действующее синхронно с художниками из США и ФРГ. Впоследствии именно московская концептуальная школа стала одним из ведущих нонконформистских движений позднесоветского времени.

В данной статье речь пойдёт об одном из эпизодов истории контактов между интеллектуалами, принадлежавшими к независимому культурному сообществу, и русской эмиграцией, а именно - о том, каким образом русские периодические издания, выходившие за рубежом, повлияли на создание нонформистского движения на ранних порах. С одной стороны, нужно определить, каким образом и в каких формах было возможно это влияние. В то же время необходимо обратить внимание на то, что идеологические основания эмигрантского сообщества и неофициальной культуры СССР не всегда совпадали. В некоторых случаях здесь можно говорить о расхождениях во взглядах или разном понимании традиций интеллектуальной свободы.

В конце 1956 г. на страницах «Граней» публикуется «Обращение антикоммунистического издательства "Посев" к деятелям литературы, искусства и науки порабощённой России», призывающее присылать или переправлять тексты, которые не могут быть опубликованы в СССР из-за несоответствия требованиям цензуры. «Российское револючионное [курсив С.С.] издательство "Посев" готово “предоставить им эту возможность"» [7]. Возможно, именно этот «революционный» призыв вызвал к жизни миф о подпольщиках и подпольной литературе.

Сначала редакция перепечатывала опубликованные тексты «молодых», но вполне официальных писателей: Евгения Евтушенко, Юрия Казакова, Юрия Нагибина, Анатолия Приставкина и др. (Грани 33, 1957 г.; Грани 43, 1959 г.). В то же время одним из первых советских авторов журнала стал опальный Борис Пастернак, который был награждён Нобелевской премией за «Доктора Живаго», но «под давлением общественности» так её и не получил (Грани 34-35, 1957 г.; Грани 36, 1957 г.; Грани 40, 1958 г.).

В начале 1960-х гг. на страницах «Граней» проводится серия публикаций московских машинописных изданий, которая открывается перепечаткой первого номера «Феникса», вышедшего в 1961 г. Он представляется как «подпольный [курсив С.С.] рукописный литературный журнал московской молодёжи», хотя такое определение не встречается ни в вошедших в него текстах, ни в анонсе другого машинописного издания - «нового поэтического сборника "Коктейль"» [17]. Тем не менее в сопроводительной статье, комментирующей публикацию «Феникса», «подпольными» названы и «Бумеранг», и «Спираль», и «Синтаксис» (Грани 52, 1962 г.) - журнал, традиционно считающийся одним из наиболее ранних московских машинописных изданий (декабрь 1959 - апрель 1960 гг.) и выходивший под редакцией Александра Гинзбурга (см. прим. 1).

Во вступительной статье к первому номеру парижского журнала «Синтаксис», озаглавленному в честь своего московского предтечи, Н. Рубинштейн комментирует эту публикацию следующим образом: «Только неправильно написано в "Гранях" - “подпольный литературный журнал"... Он и тогда так не воспринимался. Не журнал, а сборник стихов, поэтический альманах. В нём, конечно, был лёгкий приступ недозволенности, но невозможно назвать его антисоветским или подпольным. Просто - рукописный сборник...» [8].

Тем не менее в том же 1965 г. редактор нового московского литературного журнала «Сфинксы» В. Я. Тарсис (см. прим. 2), до этого публиковавшийся в «Гранях», во вступительной статье к первому номеру причисляет своё издание к разряду «так называемых “подпольных" журналов»: «Синтаксису», «Бумерангу» и «Фениксу» [15]. Возможно, с этого момента понятие «подпольной литературы» постепенно входит в обиход узкого круга московских писателей, сотрудничающих с эмигрантской прессой. Об этом также свидетельствует цитата из письма москвича, скрывшегося под инициалом «Н», которая приводится в статье К. Померанцева «Во что верит советская молодёжь?», опубликованной на 
страницах нью-йоркского «Нового Журнала»: «У нас существует настоящая подпольная литература, не политическая, конечно, а настоящая литература и поэзия. Как только исчезнет наша дурацкая цензура, вы ахнете [...] узнав, как умеют писать те, за подписью которых все привыкли читать партийно-пресные рассказы и надоедливые романы (Новый Журнал 78, 1965 г., с. 57).

Утверждать, что издательство «Посев» или эмигрантская периодика организовали компании вольных литераторов СССР в сообщество подпольной литературы, было бы преувеличением. Все-таки «Грани» в первую очередь сотрудничали с кругом столичных авторов, лишь во второй половине десятилетия пытаясь выйти за пределы литературной жизни Москвы. В частности, наладить связи с ленинградскими авторами пытался Владимир Батшев, переправивший многочисленные тексты группы СМОГ (см. прим. 3).

В 1964-65 гг. ленинградские литераторы Малой Садовой готовили машинописный альманах Fioretti. Накануне его выхода малосадовцев навестил эмиссар СМОГа. По всей видимости, решительным и бескомпромиссным молодым человеком в кожаных картузе и куртке был Владимир Батшев. Он призвал питерских поэтов объединить усилия со СМОГистами, подарил клише (резиновые матрицы) журнала «Грани» (см. прим. 4) и вселил надежду на публикацию. В. Батшев уверял, что Рада Никитична Аджубей, дочь Хрущёва и редактор журнала «Наука и жизнь», которая помогала начинающим писателям, пристроит Fioretti в какое-нибудь издательство, или же тексты напечатают в «Гранях». Возможно, ктото из малосадовцев даже подписал пакт о сотрудничестве и единении со СМОГом. Однако среди помогавших делать машинописные копии вскоре нашёлся неблагонадёжный тип. Экземпляры арестовали, затею с альманахом замяли, клише «Граней» и пакт уничтожили [3].

В результате в «Сфинксах» были опубликованы ленинградские поэты Владимир Эрль и Александр Миронов [15]. Судя по всему, именно машинописные сборники СМОГистов (рассчитанные на публикацию за пределами Союза) были импульсом для начала издательской деятельности В. Эрля - первых сборников машинописного издательства «Польза». Отличие состояло в том, что В. Эрль распечатывал только несколько экземпляров, предназначенных для близких друзей.

Косвенно и опосредованно деятельность «Граней» стимулировала развитие «машинописной» литературы, даже если была подчеркнуто аполитична, как в случае с двумя ленинградскими авторами. Но это был не единственный эмигрантский журнал, публиковавший тексты авторов из СССР как подпольную литературу. С 1960-х гг. подпольные авторы начинают печататься на страницах другого крупного эмигрантского издания - «Вестника Русского Студенческого Христианского Движения». Теперь в нём можно встретить не только материалы, касающиеся христианства, но и литературные произведения. Сначала религиозную лирику, например, подборки стихов Александры Надеждиной в рубрике «Голоса из России» (Вестник РСХД 3, 1965 г., с. 37-45). Позже, во второй половине 1960-х гг., - художественную литературу и эссеистику (Вестник РСХД 4, 1969 г., с. 58-59). Аналогично «Граням», эти публикации знакомят читателя с русской подпольной литературой. Так, журнал «Феникс-1966» представлен «подпольным» [17]. Миф «Граней» поддерживается «Вестником».

Начиная со второй половины 1960-х гг. один из главных героев «Вестника» Александр Солженицын [12]. «Грани» тоже постоянно освещают подробности его дела. Его судьба находится в центре внимания, прежде всего, по политическим мотивам. В 1970 г. «Вестник» подхватывает эстафету «Посева»: с этого времени материалы из «Хроники текущих событий» - «первого подпольного периодического издания в России» - заполняют разные рубрики журнала [17].

Круг подпольных русских писателей довольно узок. Прежде всего, к нему принадлежат авторы, которые, вступив в столкновение с советской цензурой, сумели привлечь к себе внимание зарубежной прессы и, как правило, впоследствии эмигрировали. В первую 
Савицкий С. А.

РУССКАЯ ЭМИГРАЦИЯ КАК ИНИЦИАТОР ФОРМИРОВАНИЯ НЕОФИЦИАЛЬНОГО КУЛЬТУРНОГО СООБЩЕСТВА В СССР

очередь это Александр Солженицын, Андрей Синявский, Юлий Даниэль, Иосиф Бродский, Валерий Тарсис, Владимир Войнович, Георгий Владимов, Александр Галич, Владимир Максимов, Анатолий Гладилин и некоторые другие (см. прим. 5).

Возникновение понятия «подпольная литература» можно считать началом формирования представления о литературе как антисоветской политической деятельности. Это происходит в среде эмиграции - в первую очередь в издательстве «Посев». Любопытно, что политизация неподцензурной литературы влекла за собой возобновление традиции революционно-освободительного подполья ХІХ в. В 1966 г. в Москве возобновляется издание журнала «Русское слово» - «органа радикального демократического движения, выразителя революционно-народнического мировозрения интеллигентов-разночинцев, т.н. "нигилизма"». Его новый учредитель - Клуб Рылеева - существует с 1964 г. «как преемник декабристского литературного "Общества русского слова", одним из руководителей которого был Рылеев». Из редакционной статьи к первому номеру следует, что журнал был «единственным, чем "Клуб Рылеева“" проявил себя более чем за два года своего номинального существования». Летом 1966 г. его деятельность активизировалась: 13 июля «в день 140-й годовщины со дня преступной казни источников русской свободы - Рылеева, Пестеля, Муравьева, Бестужева-Рюмина и Каховского» - сбор «Клуба Рылеева» постановил:

1. считать основой деятельности клуба стихотворение Рылеева «Гражданин» и статью «Культура и человек»;

2. избрать правление «Клуба Рылеева»;

3. вести свою работу под лозунгом «Культура, правда, честь!» [9].

В 1956 г., незадолго до выхода «Обращения», «Грани» публикуют «Подполье» первую часть «Записок из подполья» Ф. Достоевского (Грани 29, 1956 г., с. 5-26). В этом тексте высказывается критика учения о социализме, сам же автор до написания повести принадлежал к «петрашевцам».

История революционного подполья в подробностях представлена на страницах книги Марии Могильнер «Подпольная Россия» [5]. Проводя напрашивающееся сравнение, мы обнаруживаем, что послевоенная деятельность «Посева» во многом повторяет опыт революционной эмиграции второй половины XIX в., точкой отсчёта которого М. Могильнер считает книгу Сергея Степняка-Кравчинского «Подпольная Россия» (см. прим. 6). «Грани» сопровождают публикации текстов, пересланных из СССР, ссылками на петрашевцев, нигилистов, терроризм конца XIX в., и даже отсылками к декабристам. Журнал пытается подключить неподцензурную литературу в работу революционного подполья, которое на момент выхода «Обращения» (1956 г.) явно отсутствует. Результаты очевидны. Московские авторы начинают называть машинописные альманахи подпольными журналами, в течение 1960-х гг. понятие подпольной литературы постепенно входит в обиход.

Здесь нужно подробнее остановиться на двух существенных обстоятельствах. Вопервых, возникнув в результате контакта с эмиграцией и по настойчивой инициативе последней, представление о политизированной литературе и в дальнейшем фигурировало тогда, когда автор искал этого контакта, поддерживал его и так или иначе ориентировался на «запад». Во-вторых, не следует забывать о том, что имена героев революционноосвободительного движения, которые «Посев» написал на скрижалях нового антисоветского подполья, в Союзе могли вызвать ироническую улыбку, если не отторжение. Декабристы, разбудившие Герцена и последующая цепочка прерванных снов - примеры из школьных учебников по истории, набившие оскомину советские пропагандистские клише. Само подполье - широко распространённая советская мифологема революционной борьбы. С. Степняк-Кравчинский - один из её героев. Его книги охотно переиздаются в СССР как раз в 1950-е и первую половину 1960-х гг., в том числе и «Подпольная Россия» [14] (см. прим. 7).

Есть серьёзные основания сомневаться в том, что ленинградские авторы представляли себя бесстрашными борцами с коварной царской охранкой, отдавая свои стихотворения 
Владимиру Батшеву для публикации в «Гранях». Для «Посева» и русской эмиграции подполье оставалось актуальным политическим мифом. Для авторов, живших в СССР, оно было сюжетом из «Ленина в Польше» (может быть, в Париже, но точно не в Цюрихе). Здесь есть и исторический парадокс: подпольная Россия действительно предопределила многое в развитии событий, которые в конечном счёте привели к свержению монархии. Возрождая подполье в 1950-60-е гг., эмиграция воспользовалась традицией, которая сделала возможной революцию, а также последовавшие за ней первую и вторую волну эмиграции. Попытка «Посева» вдохнуть новую жизнь в подполье воспроизводила травматическую предысторию возникновения эмиграции.

Итак, политизацию неподцензурной литературы посредством обращения к традиции революционно-освободительного подполья XIX в. можно считать начальным этапом в формировании представления о литературе как антисоветской деятельности. Оно было инициировано контактом с эмиграцией, который можно рассматривать в качестве одного из непременных условий политизации литературы позднего социализма в целом. Понятие подполья было распространено в определённом кругу Москвы 1960-х гг., но впоследствии практически полностью вышло из употребления (см. прим. 8). Подпольная литература была одним из первых определений для авторов, испытывавших трудности с публикацией своих текстов в Союзе. Уже в конце 1950-60-х гг. у него появляются синонимы «несозвучная литература», «потаённая литература» и «самиздат» - серьёзный конкурент, возникший изнутри советской культуры. В течение 1970-х гг. о подполье окончательно забывают, начиная путаться в сложном нагромождении новых названий: неофициальная, независимая, неподцензурная, вторая, третья литературы, а также литературы андеграунда, андерграунда, сопротивления, контр-культуры и некоторых других.

\section{ЛИТЕРАТУРА}

1. Вестник Русского Студенческого Христианского Движения. 1925 - 2016.

2. Грани. Журнал литературы, искусства и общественно-политической мысли. Frankfurt am Mein. $1946-2016$.

3. Интервью с Андреем Гайворонским. 9.02.1998.

4. Мальцев, Ю. Вольная русская литература: 1955 - 1975. Frankfurt am Main, 1976.

5. Могильнер, М. Мифология «подпольного человека»: радикальный микрокосм в России начала ХХ века как предмет семиотического анализа / М. Могильнер. - М., 1999. - 208 с.

6. Новый Журнал. Нью-Йорк, 1942 - 2016.

7. Обращение антикоммунистического издательства «Посев»к деятелям литературы, искусства и науки порабощённой России // Грани 32. - 1956. - С. 3-6.

8. Рубинштейн, Н. Когда труба трубила о походе... / Н. Рубинштейн // Синтаксис 1. - 1978. - С. $3-7$.

9. «Русское слово» - литературный и общественный журнал. Москва 1966 г. // Грани 66. - 1967. C. 3-34.

10. «Синтаксис» №o 1-3 - подпольный литературный журнал московской и ленинградской молодёжи // Грани 58. - 1965. - С. 95-193.

11. Советская потаенная муза: из стихов советских поэтов, написанных не для печати. - Мюнхен, 1961.

12. Солженицын, А. Письмо 4-му Всесоюзному Съезду Советских Писателей / А. Солженицын // Вестник Русского Студенческого Христианского Движения. - 1967. - № 2 (84). - С. 5-10.

13. Степняк-Кравчинский, С. Сочинения. В 2 т. / С. Степняк-Кравчинский. - М., 1958.

14. Степняк-Кравчинский, С. Подпольная Россия / Степняк-Кравчинский. - М., 1960.

15. «Сфинксы» № 1 - литературный российский журнал // Грани 59. - 1965. - С. 7-77.

16. Тарсис и эмиграция. [Б.М.], 1966.

17. «Феникс» - журнал московской молодёжи // Грани 52. - 1962. - С. 86-190.

18. Хроника текущих событий $15,1970$. 
Савицкий С. А.

РУССКАЯ ЭМИГРАЦИЯ КАК ИНИЦИАТОР ФОРМИРОВАНИЯ НЕОФИЦИАЛЬНОГО КУЛЬТУРНОГО СООБЩЕСТВА В СССР

\section{ПРИМЕЧАНИЯ}

1. Определение «подпольная» литература встречается во вступительной статье к сборнику «Советская потаённая муза», вышедшему в Мюнхене в 1961 г. [11, 7]. В 1965 г., спустя пять лет после «издания», на страницах «Граней» помещены три номера «Синтаксиса» [10].

2. См. о нём в [16].

3. Видимо, благодаря знакомству с В. Таршисом. О СМОГе см.: Грани 60 и 61, 1966 г., а также Грани 63, 1967 г.

4. По всей видимости, выпуск альманаха «Сфинксы».

5. В середине 1970-х гг. понятие «подпольной литературы» приобретает более широкое распространение за пределами Союза благодаря книге Юрия Мальцева «Вольная русская литература», вышедшей в том же издательстве «Посев» [4]. В этом критическом обзоре послевоенной русской литературы представлено неизмеримо больше авторов.

6. Книга была написана по-итальянски и опубликована в одной из миланских газет в 1881-1882 гг. В русском переводе текст был издан лишь в 1893 г. в Лондоне.

7. См. также его собрание сочинений [13].

8. В 1980-е гг. оно вновь входит в обиход в рок-культуре, игравшей одну из первостепенных ролей в неофициальном сообществе накануне Перестройки. 